\title{
ESTUDO SOBRE RIGIDEZ DE PREÇOS NO BRASIL: UMA ABORDAGEM SETORIAL COM INFORMAÇÕES AGREGADAS*
}

\author{
Jocildo Fernandes Bezerra ${ }^{\dagger}$ \\ Igor ÉzIO MaCiel Silva $\ddagger$
}

\begin{abstract}
Resumo
Utilizando os componentes não observados dos produtos real e nominal estima-se modelo DSGE semi-estrutural de rigidez de preços que varia entre os setores. Exercício Monte Carlo testa a similitude da estrutura de preços do Brasil versus Estados Unidos e um modelo de Markov analisa a estabilidade da política monetária no período de 1996:1 a 2015:4. Revelam-se distribuições de rigidez de preços e graus de complementaridade estratégica e comparam-se as persistências dos efeitos dos choques nominais no produto e na inflação entre os cenários de homogeneidade e heterogeneidade estrutural. Neste último caso há vantagem substancial para identificar as propriedades dinâmicas dessas variáveis.
\end{abstract}

Palavras-chave: heterogeneidade, rigidez de preços, DSGE semi-estrutural.

\begin{abstract}
Using unobserved components of real and nominal products, we estimated a semi-structural DSGE model of price rigidity with structural heterogeneity. We tested the similarity of the price structure in Brazil compared to that of the United States and analyzed the stability of monetary policy from 1996:Q1 until 2015:Q4. Price rigidity distributions and degrees of strategic complementarities were verified and the persistence of the effects of nominal shocks on product and inflation are compared between scenarios of homogeneity and structural heterogeneity. The latter case showed a substantial advantage in identifying the dynamic properties of these variables.
\end{abstract}

Keywords: heterogeneity, price rigidity, semi-structural DSGE.

JEL classification: E10, E30.

DOI: http : / / dx.doi .org/10.11606/1980-5330/ea 151245

\footnotetext{
* Extraído do segundo capítulo da Tese de Professor Titular do $1^{\circ}$ autor.

† Universidade Federal de Pernambuco. E-mail: jocildo.bezerra@gmail.com

‡ Universidade Federal do Rio Grande do Norte. E-mail: igormacielsilva@gmail.com
} 


\section{Introdução}

A hipótese sobre rigidez de preços, embora antiga (LUCAS JUNIOR 1996), ganhou força no pensamento econômico a partir de KEYNES (1936) e adquiriu um caráter dinâmico com os trabalhos de FISCHER (1977), TAYLOR (1979), TAYLOR (1980) e CALVO (1983), os quais contribuíram não só para suportar a evidência empírica sobre os impactos reais dos choques nominais, mas, também, para permitir a avaliação dos efeitos de políticas monetárias alternativas.

A literatura recente tem apontado, no entanto, que esses trabalhos pioneiros não refletem um aspecto instigante, presente nos microdados, qual seja, que existe heterogeneidade setorial na frequência de ajustamento de preços e que isso, do ponto de vista macroeconômico, tem implicações consideráveis para os efeitos da política monetária.

Entre os trabalhos mais importantes que trataram sobre a questão em nível de microdados, destacam-se BILS \& KLENOW (2004), KLENOW \& KRYVTSOV (2008), NAKAMURA \& STEINSSON (2008), para os Estados Unidos, enquanto DHYNE et al. (2006), VERMEULEN et al. (2007) e ÁLVAREZ et al. (2005) estudaram o assunto para diversos países da Europa.

TAYLOR (1998), revendo a evidência sobre fixação de preços em nível micro, chega à conclusão de que algum nível de heterogeneidade na forma como os preços são estabelecidos é necessário para descrever a realidade de modo mais acurado.

As implicações macroeconômicas da heterogeneidade setorial na fixação de preços foram contempladas, entre outros, por CARVALHO (2006), CARLSTROM et al. (2009), DIXON \& KARA (2005), DIXON \& KARA (2011), CARVALHO \& DAM (2010), IMBS et al. (2011), FLAMINI (2014), CARVALHO et al. (2015).

O objetivo deste trabalho é contribuir para o debate por meio da estimação, para o Brasil, de um modelo de Equilíbrio Geral Dinâmico e Estocástico (Dynamic Stochastic General Equilibrium - DSGE) semi-estrutural de rigidez de preços, em que o grau de rigidez varia entre os setores, examinando a dinâmica conjunta do produto e da inflação, em reposta a choques nominais e comparando-a com o cenário, dito homogêneo, em que todas as empresas da economia adotam a mesma duração de preços. Os recursos usados neste trabalho para acessar o comportamento dinâmico das variáveis são: as funções impulso-resposta (FIR), no caso do produto real, e o grau de reversão à média (MARQUES 2004) no caso da inflação. A variável inflação será simulada por meio do modelo DSGE.

Ademais, realiza-se um exercício Monte Carlo para testar a similitude da estrutura de preços do Brasil com a dos Estados Unidos e, através de um modelo de Markov, analisa-se a estabilidade da política monetária no período abrangido pelo estudo, 1996:1 a 2015:4.

O modelo aqui estimado segue CARVALHO \& DAM (2010) e CARVALHO et al. (2015), mas incorpora as seguintes diferenças: primeiro, aqueles autores usaram uma abordagem Bayesiana e aqui se usa máxima verossimilhança; em segundo lugar, aqui serão usados os componentes não observados das séries (HARVEY 2011, COMMANDEUR \& KOOPMAN 2007, KOOPMANS \& OOMS 2010). Também, será verificada a estabilidade do regime de política monetária e, finalmente, para testar se a dinâmica setorial torna mais persistentes os efeitos dos choques nominais sobre a inflação, do que no caso da economia 
homogênea, será usada a técnica de identificar a reversão da inflação à sua média.

O trabalho se relaciona a vários ramos da literatura, entre eles o que trata de identificar distribuições de durações de preços a partir de dados agregados (JADRESIC 1999, TAYLOR 1993, CARVALHO \& DAM 2010); à literatura que trata dos modelos semi-estruturais (CARVALHO \& DAM 2010, KICHIAN et al. 2010, CHARRY et al. 2014, SBORDONE 2002); e, também, aos modelos que tratam sobre complementaridade estratégica (ALVI 1993, AMITI et al. 2016, WOODFORD 2003, ROMER 2012).

Entre os resultados obtidos, observa-se que $28 \%$ dos preços duram um trimestre e $46 \%$ duram dois trimestres, ou seja, $46 \%$ das firmas mudam os preços pelo menos uma vez ao ano. Por outro lado, a estimação do modelo de heterogeneidade estrutural considerando-se seis setores, gera valor do parâmetro de complementaridade estratégica de aproximadamente 0,13 , o qual se situa entre 0,10 e 0,15 , intervalo que, segundo WOODFORD (2003), é consistente com modelos de especificação completa.

O restante deste trabalho se estrutura da seguinte forma: na segunda parte, apresentam-se breves informações sobre a literatura; na terceira parte, apresentamse os dados e a metodologia; na quarta parte, analisam-se os resultados e, finalmente, são oferecidas algumas conclusões.

\section{Literatura}

Considera-se, em primeiro plano, a questão da rigidez de preços causada pelo ajustamento escalonado, em que se destaca a obra de TAYLOR $(1979,1980$, $1998,2016)$, da qual se origina o modelo utilizado neste trabalho, qual seja, CARVALHO \& DAM (2010).

TAYLOR (1979) parte da percepção de que o componente representativo da inflação esperada, na equação da curva de Phillips aceleracionista, é independente do comportamento dos agentes e, portanto, não reflete à dinâmica dos contratos de preços e salários, sendo essa dinâmica indispensável na explicação da persistência da inflação ${ }^{1}$. Necessário, pois, dedicar atenção à curva de Phillips de curto prazo, e à sua dinâmica, para uma compreensão correta dos efeitos dos choques nominais, levando em conta que nesse contexto há dois fenômenos em causa, a saber: as expectativas racionais e os contratos; e a persistência, ou não, decorrente da rigidez de preços, depende de qual das duas forças é dominante.

Mais tarde, apareceram os modelos setoriais enfatizando o papel dos preços relativos na propagação dos choques, predominantemente choques nominais. AOKI (2001) propõe um modelo de dois setores com, respectivamente, preço flexível e preço rígido e analisa a relação entre as mudanças nos preços relativos e as flutuações da inflação.

CARLSTROM et al. (2009) usam um modelo de dois setores com diferentes graus de rigidez de preços, com imobilidade do fator trabalho, e associam o efeito autorregressivo da razão de preços relativos à persistência do produto e da inflação.

\footnotetext{
${ }^{1}$ ROMER (2012) diz que essa independência da inflação esperada em relação ao ambiente econômico acaba por implicar na instabilidade da curva de Phillips tanto quanto na sua versão antiga.
} 
DIXON \& KARA $(2005,2011)$ com um modelo de equilíbrio geral dinâmico, equilíbrio geral dinâmico (DGE), propõem uma abordagem que generaliza o modelo original de TAYLOR (1980) para incorporar os efeitos de diferentes setores com contratos de diferentes durações. Esse modelo engloba a economia original de Taylor como um caso especial onde há apenas uma duração de preços para todos os contratos.

Em CARVALHO (2006), revive-se o papel dos preços relativos destacandose suas diferentes distribuições durante o processo de ajustamento, a um choque nominal, em um contexto de contratos setoriais com diferentes durações. Para esse autor, as mudanças nas distribuições de preços relativos são a razão de "efeitos não triviais" na dinâmica agregada. As distribuições, por sua vez, são geradas por dois tipos de reações dos agentes, que se manifestam em presença de heterogeneidade setorial: (i) efeito composição de frequência; e (ii) complementaridade estratégica.

Na literatura que emprega modelos semi-estruturais, destacam-se KICHIAN et al. (2010), que propõem equações únicas para prever o comportamento futuro da inflação no Canadá, no curto e no médio prazos. Os modelos combinam aspectos estruturais da Curva de Phillips Novo Keynesiana (NKPC), incluindo, alternativamente, economia fechada e aberta, com as características das séries temporais presentes nos dados.

CHARRY et al. (2014) desenvolvem e aplicam um modelo semi-estrutural para analisar a política monetária em Ruanda e a introdução das séries temporais (dados observados) no modelo permite ilustrar as contribuições de vários fatores para a dinâmica da inflação daquele país, bem como os seus desvios da meta.

$\mathrm{Na}$ literatura brasileira, os trabalhos mais recentes nessa área, ao que parece, são: MINELLA \& SOUZA SOBRINHO (2009) e KRZNAR \& MATHESON (2017). No primeiro, o objetivo dos autores é estudar os canais de transmissão da política monetária. O modelo é constituído de cinco blocos de equações compreendendo a demanda agregada, a oferta agregada, o setor financeiro, a política monetária e o resto do mundo. Este último bloco é constituído por processos estocásticos exógenos representados por $\operatorname{ARMA}(p, q)$ e $\operatorname{AR}(p)$. No segundo trabalho, os autores exploram a relação entre ciclo econômico e ciclo financeiro no Brasil, o que fazem com o emprego de métodos estatísticos comumente utilizados e com um modelo semi-estrutural da economia brasileira, empregando uma abordagem Bayesiana.

\section{Dados e Metodologia}

\subsection{Dados}

Os dados empregados neste trabalho são as séries temporais, de periodicidade trimestral, representativas do PIB real e do PIB nominal, obtidas nas Contas Nacionais Trimestrais do Instituto Brasileiro de Geografia e Estatística (IBGE), e a taxa Selic-over obtida na base de dados do Instituto de Pesquisa Econômica Aplicada (Ipea). Das séries temporais do PIB, lhes são extraídos os seus componentes não observados, usando a metodologia proposta em: HARVEY (1989), COMMANDEUR \& KOOPMAN (2007), KOOPMANS \& OOMS (2010) e esses são usados no processo de estimação do modelo. A taxa Selic-over, nas suas versões nominal e real, é usada para estimar o modelo de Markov como 
forma de avaliar a estabilidade da política monetária no período estudado, 1996:1 a 2015:4.

Esta parte do trabalho se inicia com a aplicação do modelo de Markov para testar a estabilidade do regime de política monetária, no Brasil, no período em estudo, isto é, 1996:1 a 2015:4. A hipótese de estabilidade é fundamental para a confiabilidade dos resultados, conforme CARVALHO \& DAM (2010), DAVIG \& DOH (2014), COENEN \& LEVIN (2004).

Há na literatura muitos trabalhos demonstrando os efeitos de mudanças no regime de política monetária sobre a taxa real de juro (RESCHREITER 2011, CAPORALE \& GRIER 2005, HUIZINGA \& MISHKIN 1985, WU \& ZENG 2006) e sobre a taxa nominal de juro (FUJIWARA 2006). Por outro lado, um instrumental de econometria muito usado por esses autores para analisar o fenômeno é o modelo de mudança de regime de Markov (DUPASQUIER \& RICKETTS 1998, EVANS \& LEWIS 1995, WU \& ZENG 2006, GARCIA \& PERRON 1996, FUJIWARA 2006).

A forma mais simples de especificar tal modelo estabelece que $s_{t}$ é o evento de uma corrente de Markov de dois estados. Assim,

$$
P_{r}\left(s_{t}=j \mid s_{t-1}=i\right)=P_{i j}
$$

Tendo em vista que $s_{t}$ não é observado diretamente, mas apenas objeto de inferência através do comportamento da série $y_{t}$, os parâmetros necessários para descrever completamente a lei de probabilidade que governa $y_{t}$ são: $\sigma^{2}, \phi$, $\mu_{1}, \mu_{2}, P_{11}, P_{12}$, nessa ordem, representando a variância dos erros, a inclinação, os interceptos, antes e depois da mudança de regime, e as probabilidades dos dois estados de transição ${ }^{2}$. Se a mudança é permanente, ela é representada por $P_{12}=1$.

As Figuras 1 e 2 apresentam os resultados dos testes de estabilidade do regime de política monetária no Brasil, usando as taxas de juro real e nominal. Observa-se, em conformidade com as estimativas do modelo de Markov, que a mudança de regime ocorrida em 1999 foi permanente. A Figura 1, considerando a taxa de juro real, parece constatar uma mudança de regime. Na Figura 2, considerando a taxa de juro nominal, há indícios de que mesmo antes de 1999 o Brasil já adotava procedimento equivalente àquele vigente a partir de 2000. Como há um debate na literatura ${ }^{3}$ sobre qual a taxa de juro é mais adequada para o exercício aqui realizado, optou-se por utilizar, nas estimações do modelo DSGE, os dados do período completo, 1996:1 a 2015:4 e a qualidade dos resultados das estimações parece confirmar o acerto dessa decisão.

\subsection{O Modelo DSGE Semi-Estrutural}

\section{Especificação do Modelo Semi-Estrutural ${ }^{4}$}

Dada a natureza novo Keynesiana do modelo, a sua hipótese central pressupõe um continuum de firmas em concorrência monopolística. Para destacar a questão de interesse neste trabalho, isto é, a heterogeneidade setorial, supõese, ademais, que as firmas estão distribuídas em $K$ setores da economia, sendo

\footnotetext{
${ }^{2}$ Seguindo a anotação de DOAN (2010). Por limitação de espaço, não se apresentam as regressões.

${ }^{3}$ Ver HUIZINGA \& MISHKIN (1985) e GARCIA \& PERRON (1996).

${ }^{4}$ Baseado em CARVALHO \& DAM $(2009,2010)$
} 
Figura 1: Evolução da taxa de juro real e probabilidade de não mudança do regime de política monetária

(a) Taxa de Juros Real

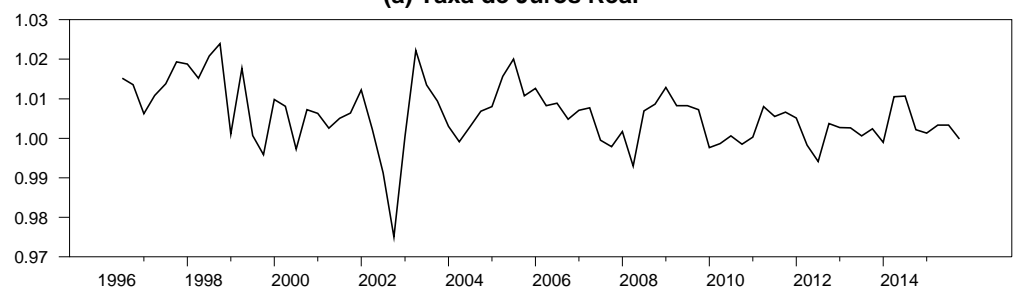

(b) Probabilidade do Regime №o Mudar

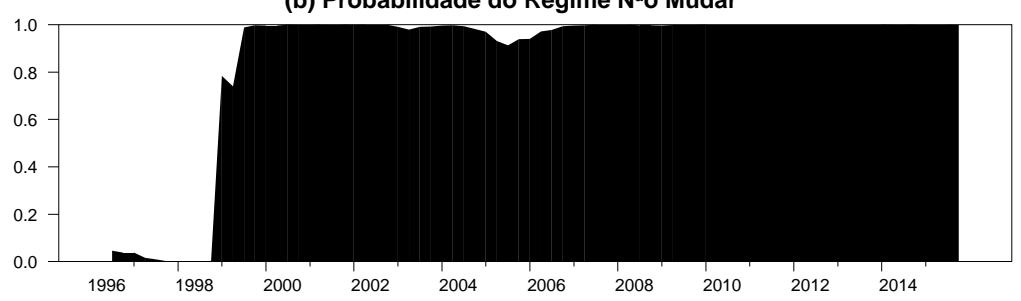

Fonte: Elaborado pelos autores.

Figura 2: Evolução da taxa de juro nominal e probabilidade de não mudança do regime de política monetária

(a) Taxa de Juros Real

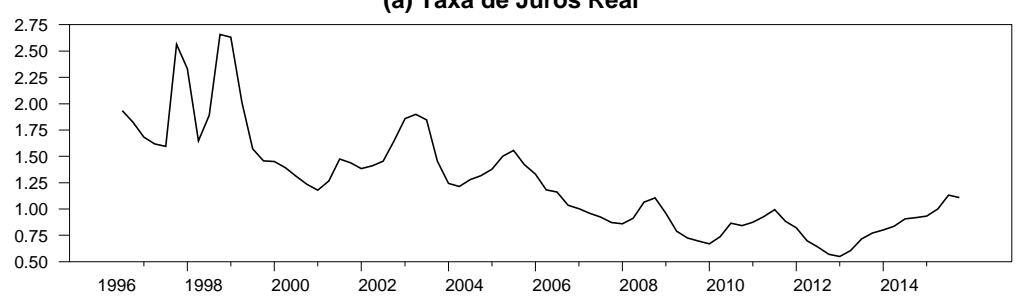

(b) Probabilidade do Regime №a $\mathrm{o}$ Mudar

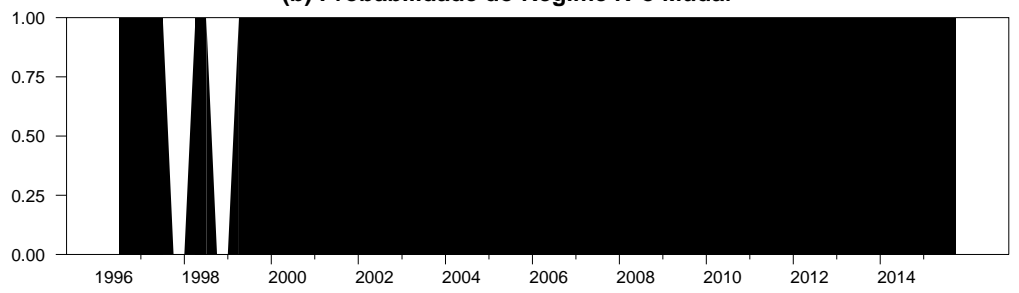

Fonte: Elaborado pelos autores. 
que diferentes setores implicam diferentes frequências de mudanças de preços. As firmas são indexadas por $k \in(1, \ldots, K)$, e por $j \in(0, \ldots, 1)$. A densidade de firmas em cada setor é representada por $\left(\omega_{1}, \ldots, \omega_{K}\right)$, com $\omega_{K} \geq 0$ e $\sum_{k=1}^{K} \omega_{k}=1$, onde $\omega_{k}$ é a densidade de firmas no setor $k$. Cada firma produz um único bem e enfrenta uma demanda que depende, negativamente, do seu preço relativo.

O lucro da firma $j$ pertencente ao setor $k$, é representado por:

$$
\Pi(k, j)=P_{t(k, j)} Y_{t(k, j)}-C\left(Y_{t(k, j)}, Y_{t}, \xi_{t}\right)
$$

onde $P_{t(k, j)}$ é o preço cobrado pela firma $j$ do setor $k, Y_{t(k, j)}$ é a quantidade vendida pela firma $j$ do setor $k, C\left(Y_{t(k, j)}, Y_{t}, \xi_{t}\right)$ é o custo em que a firma incorre para produzir, que depende tanto da quantidade que ela produz, como também do produto total da economia, $Y_{t}$, e está sujeito ao choque $\xi_{t}$. O preço relativo da firma é:

$$
\frac{P_{t(k, j)}}{P_{t}}
$$

em que $P_{t}$ é o nível geral de preços (NGP).

Assim, a função lucro, $\Pi(k, j)\left(P_{t(k, j)}, Y_{t(k, j)}, Y_{t}, \xi_{t}\right)$, é homogênea de grau 1 nos seus dois primeiros argumentos, tem um único ponto de máximo que depende de $P_{t(k, j)}$ independentemente dos valores das demais variáveis.

O NGP é uma média representada por $\Gamma\left(P_{t(k)}, W_{k(k=1, \ldots, K)}\right)$, onde $\Gamma$ é um operador de agregação homogêneo em $P_{t(k)}$, e $P_{t(k)}=\Lambda\left(P_{t(k, j)}\right), j \in(0,1)$.

Com base em TAYLOR $(1979,1980)$, supõe-se que a firma contratará um preço que permanecerá fixo por um dado número de períodos que vale para todas as firmas do setor, de modo que os preços contratados são específicos dos setores. Assim, no setor 1 o preço durará 1 período, no setor 2, durará 2 períodos, e assim sucessivamente, contando, ainda, que no corte setorial os preços são escalonados. Dessa forma, o conjunto $\omega=\left(\omega_{1}, \ldots, \omega_{K}\right)$ é suficiente para caracterizar a distribuição cross-section de rigidez de preços que se objetiva estimar.

Considerando uma firma que contrate um preço $X_{t(k, j)}$ para $k$ períodos, pode-se escrever como a seguir a equação que ela precisa maximizar, ou seja:

$$
\max E_{t} \sum_{i=0}^{k-1} Q_{t, t+i} \Pi\left(X_{t(k, j)}, P_{t+i}, Y_{t+i}, \xi_{t+i}\right)
$$

onde $Q_{t, t+i}$ é um fator de desconto, que pode ser estocástico, implicando uma condição de primeira ordem de maximização de lucro da firma da seguinte forma:

$$
E_{t} \sum_{i=0}^{k-1} Q_{t, t+i} \frac{\partial \Pi\left(X_{t(k, j)}, P_{t+i}, Y_{t+i}, \xi_{t+i}\right)}{\partial X_{t(k, j)}}=0
$$




\section{Loglinearizando o Modelo}

A Equação (1) é loglinearizada em torno de uma trajetória de equilíbrio determinístico na qual $M_{t}=\bar{M}, \xi_{t}=\bar{\xi}, Y_{t}=\bar{Y}, Q_{t, t+i}=\beta^{i}$, e $X_{t(k, j)}=P_{t}=\bar{P}$, para todo $(k, j)$, de modo a se obter:

$$
x_{t(k)}=\frac{1-\beta}{1-\beta^{k}} E_{t} \sum_{i=0}^{k-1} \beta^{i}\left(p_{t, i}+\zeta\left(y_{t+i}-y_{t+i}^{n}\right)\right)
$$

Variáveis minúsculas denotam logaritmos dos desvios em relação às suas tendências, o parâmetro $\zeta$ representa índice de rigidez real identificado em BALL \& ROMER (1990). $y_{t+i}^{n}$ representa o produto natural e é definido implicitamente em função de $\zeta$ quando a firma alcança o seu preço de maximização de lucro. O fato de $y_{t+i}^{n}$ se mover proporcionalmente a $\zeta$ significa que, em presença de um choque, a empresa opta pelo produto de lucro máximo em uma economia de preços flexíveis.

O produto nominal é representado pela equação a seguir:

$$
m_{t}=p_{t}+y_{t}
$$

As Equações (4) e (5) são aproximações loglineares dos níveis, geral e setorial, de preços:

$$
\begin{gathered}
p_{t}=\sum_{k=1}^{K} \omega_{k} p_{t(k)} \\
p_{t(k)}=\frac{1}{k} \sum_{j=0}^{k-1} x_{t-k(k)}
\end{gathered}
$$

Agora, substituindo-se a Equação (3) na Equação (2), é possível destacar o papel da rigidez real na influencia dos choques de demanda sobre os reajustes de preços.

$$
x_{t(k)}=\frac{1-\beta}{1-\beta^{k}} E_{t} \sum_{i=0}^{k-1} \beta^{i}\left(\zeta\left(m_{t+i}-y_{t+i}^{n}\right)+(1-\zeta) p_{t+i}\right)
$$

O parâmetro $\zeta$ conta a história sobre a complementaridade estratégica. Aqui, pode-se observar que, quanto menor ele for, mais próximo de $p_{t+i}$ estará o preço contratado em $t, x_{t(k)}$ e, também, mais independente será de choques da demanda, o que aumenta a rigidez nominal e acentua a não neutralidade da moeda.

\section{Os Processos Estocásticos Exógenos}

Completa-se o modelo especificando-se os processos estocásticos exógenos que representam as dinâmicas do PIB nominal $\left(m_{t}\right)$ e do PIB natural $\left(y_{t}^{n}\right)^{5}$. Esses processos estocásticos são responsáveis pela geração dos choques que vão impactar o produto e a inflação nas estimativas do modelo. O procedimento está em conformidade com o que é exigido no processo de estimação

\footnotetext{
${ }^{5}$ Sempre lembrando que neste trabalho, ao invés das séries brutas obtidas nas bases de dados oficiais, trabalha-se com os componentes não observados dessas séries.
} 
de um DSGE com dados factuais, isto é, que o número de choques seja igual ao número de observáveis (Estima 2014).

Em consonância com CARVALHO \& DAM $(2009,2010)$, assumem-se os dois processos estocásticos, sendo um deles $A R(p 1)$ para $m_{t}$ :

$$
m_{t}=\rho_{0}+\rho_{1} m_{t-1}+\cdots+\rho_{p 1} m_{t-p 1}+\epsilon_{t}^{m},
$$

e outro $A R(p 2)$ para $y_{t}^{n}$ :

$$
y_{t}^{n}=\delta_{0}+\delta_{1} y_{t-1}^{n}+\cdots+\delta_{p 2} y_{t-p 2}^{n}+\epsilon_{t}^{n},
$$

onde $\epsilon_{t}=\left(\epsilon_{t}^{m}, \epsilon_{t}^{n}\right)$ e $\epsilon_{t} N\left(0_{1 \times 2}, \Omega^{2}\right)$, com $\Omega^{2}=\left[\begin{array}{cc}\sigma_{m}^{2} & 0 \\ 0 & \sigma_{n}^{2}\end{array}\right]$

\section{O Modelo na Forma Estado-Espaço}

Uma vez especificado o modelo, o passo seguinte é colocá-lo na forma estadoespaço para que possa ser resolvido. A forma estado-espaço é constituída por todas as fórmulas geradas pelo modelo original. No presente caso, as Equações (1) a (8) motivaram a construção de 21 fórmulas que serão agrupadas e expressas como um sistema de matrizes. O algoritmo usado é o método QZ de SIMS (2002).

Antes, porém, tem-se que lembrar que há duas classes de elementos que precisam ser explicitados para que o modelo esteja bem informado e possa ser resolvido; ou seja, é necessário classificar o que são as séries e o que são os parâmetros. O modelo DSGE trabalha simbolicamente com séries e numericamente com parâmetros.

Isto posto, a forma estado-espaço pode ser representada, em sua expressão reduzida, por

$$
Z_{t}=C(\theta)+G_{1}(\theta) Z_{t-1}+B(\theta) \epsilon_{t}
$$

onde o vetor $\theta$ contém os parâmetros primitivos do modelo, isto é:

$$
\theta=\left(K, p_{1}, p_{2}, \beta, \zeta, \sigma_{m}, \sigma_{n}, \omega_{1}, \ldots, \omega_{K}, \rho_{1}, \ldots, \rho_{p 1}, \delta_{1}, \ldots, \delta_{p 2}\right) .
$$

Para modelos que admitem completa descrição dos observáveis, uma das técnicas de estimação é máxima verossimilhança, cuja essência consiste na avaliação do modelo estado-espaço ${ }^{6}$.

\subsection{A Estratégia Empírica}

Tudo o que foi discutido no item anterior tem que passar pelo teste crucial de operacionalidade no que concerne à possibilidade de se extraírem distribuições setoriais de preços para a economia brasileira a partir dos seus dados agregados representados pelas componentes não observadas do produto nominal e do produto real.

\footnotetext{
${ }^{6}$ Para uma descrição de como se procede com a função likelihood obtida a partir do emprego do filtro de Kalman, veja-se CARVALHO \& DAM $(2009,2010)$ e DOAN (2010).
} 
Neste sentido, este trabalho se orienta por duas importantes evidências existentes na literatura. A primeira delas se deve a KLENOW \& MALIN (2010), os quais afirmam que a duração média dos preços em mercados emergentes é próxima da encontrada para os Estados Unidos e região do Euro. A segunda evidência vem de GOUVEA (2007), cujos resultados indicam que a heterogeneidade na fixação de preços entre os diversos setores no Brasil é similar àquela para os Estados Unidos e região do Euro.

O que está em pauta é um problema de identificação, ou seja, como a distribuição cross-section de rigidez de preços $\omega=\left(\omega_{1}, \ldots, \omega_{K}\right)$ pode ser revelada a partir do emprego de apenas duas variáveis representando, respectivamente, o PIB nominal e o PIB real da economia brasileira ${ }^{7}$ ?

Para testar a semelhança entre as estruturas de preços, citadas acima, realizase um exercício Monte Carlo, seguindo CARVALHO \& DAM (2009, 2010), comparando os resultados desses autores com os obtidos aqui. Esse exercício é sustentado pelos parâmetros dos processos $\mathrm{AR}(2)$ obtidos dos componentes não observados do produto nominal e do produto real, do Brasil, e respectivos choques. Com base nos resultados de KLENOW \& MALIN (2010) e GOUVEA (2007), os guesses de distribuição de preços para a implementação do exercício são os mesmos usados por CARVALHO \& DAM $(2009,2010)$ para a economia americana, isto é, $K=4, \omega=(0,4 ; 0,1 ; 0,1 ; 0,4)$ e $\beta=0,99$.

Em ambos os casos as estimações são feitas através de máxima verossimilhança. A Tabela 1 compara os resultados desse exercício para o Brasil e para os Estados Unidos, em testes para pequenas amostras e para grande amostra, constatando grande similitude das médias obtidas para os parâmetros $\zeta, \omega_{1}, \omega_{2}, \omega_{3}$ e $\omega_{4}$. O teste de pequena amostra realizado por CARVALHO \& $\operatorname{DAM}(2009,2010)$ simulou 240 amostras de 100 observações; neste trabalho, para o mesmo teste, fizeram-se duas simulações, sendo uma de 240 amostras e 80 observações, e outra de 300 amostras de 80 observações.

Para o teste de grande amostra, 1000 observações foram simuladas 100 vezes, no caso deste trabalho, e 75 vezes em CARVALHO \& DAM $(2009,2010)$. Essas simulações mostram uma aproximação ainda maior. As evidências quanto aos intervalos de confiança repetem o observado anteriormente. Em primeiro lugar, todos os intervalos estimados neste estudo contêm as médias estimadas no estudo de referência ${ }^{8}$; e em segundo lugar, os intervalos de confiança deste trabalho são relativamente mais precisos.

Diante dessas constatações, parece correto afirmar-se que o modelo é aplicável à economia brasileira e que as variáveis agregadas, utilizadas no exercício, contêm informações sobre distribuições setoriais de durações de preços, hipótese à qual será dado conteúdo prático na próxima seção.

\section{Estimações dos Componentes Não Observados}

Antes de se iniciarem as estimações, chama-se a atenção para o fato de que há precedentes na literatura sobre a utilização de componentes não observados em regressões que são formas reduzidas de modelos mais gerais, sendo as estimações da curva de Phillips um arquétipo frequente. Assim, por exemplo, WONGWACHARA \& MINPHIMAI (2009) extraem o gap do produto como componente não observado do PIB e o empregam na estimação da curva de

\footnotetext{
${ }^{7}$ Nesse caso, os componentes não observados dessas duas variáveis.

${ }^{8}$ Refere-se ao trabalho de CARVALHO \& DAM (2010).
} 
Tabela 1: Exercício Monte Carlo comparativo: estimação por máxima verossimilhança

\begin{tabular}{|c|c|c|c|c|c|}
\hline \multirow[b]{2}{*}{ Parâmetros } & \multicolumn{2}{|c|}{ CARVALHO \& DAM $(2009,2010)$} & \multicolumn{3}{|c|}{ Este Trabalho } \\
\hline & $\begin{array}{c}240 \text { Draws e } \\
100 \text { Observações }\end{array}$ & $\begin{array}{c}75 \text { Draws e } \\
1000 \text { Observações }\end{array}$ & $\begin{array}{c}240 \text { Draws e } \\
80 \text { Observações }\end{array}$ & $\begin{array}{c}300 \text { Draws e } \\
80 \text { Observações }\end{array}$ & $\begin{array}{c}100 \text { Draws e } \\
1000 \text { Observações }\end{array}$ \\
\hline$\zeta$ & $\begin{array}{c}0,179 \\
{[0,0220,415]}\end{array}$ & $\begin{array}{c}0,106 \\
{[0,0590,150]}\end{array}$ & $\begin{array}{c}0,154 \\
{[0,0310,398]}\end{array}$ & $\begin{array}{c}0,159 \\
{[0,0700,279]}\end{array}$ & $\begin{array}{c}0,104 \\
{[0,0570,151]}\end{array}$ \\
\hline$\omega_{1}$ & $\begin{array}{c}0,395 \\
{[0,1830,621]}\end{array}$ & $\begin{array}{c}0,395 \\
{[0,1830,621]}\end{array}$ & $\begin{array}{c}0,347 \\
{[0,0000,767]}\end{array}$ & $\begin{array}{c}0,280 \\
{[0,1580,354]}\end{array}$ & $\begin{array}{c}0,396 \\
{[0,2690,541]}\end{array}$ \\
\hline$\omega_{2}$ & $\begin{array}{c}0,096 \\
{[0,0000,376]}\end{array}$ & $\begin{array}{c}0,100 \\
{[0,0000,257]}\end{array}$ & $\begin{array}{c}0,110 \\
{[0,0000,286]}\end{array}$ & $\begin{array}{c}0,110 \\
{[0,0000,262]}\end{array}$ & $\begin{array}{c}0,098 \\
{[0,0620,130]}\end{array}$ \\
\hline$\omega_{3}$ & $\begin{array}{c}0,088 \\
{[0,0000,304]}\end{array}$ & $\begin{array}{c}0,091 \\
{[0,0000,197]}\end{array}$ & $\begin{array}{c}0,100 \\
{[0,0000,290]}\end{array}$ & $\begin{array}{c}0,110 \\
{[0,0000,249]}\end{array}$ & $\begin{array}{c}0,102 \\
{[0,0640,135]}\end{array}$ \\
\hline$\omega_{4}$ & $\begin{array}{c}0,498 \\
{[0,0640,801]}\end{array}$ & $\begin{array}{c}0,414 \\
{[0,2330,570]}\end{array}$ & $\begin{array}{c}0,440 \\
{[0,1620,719]}\end{array}$ & $\begin{array}{c}0,499 \\
{[0,3650,645]}\end{array}$ & $\begin{array}{c}0,404 \\
{[0,2950,500]}\end{array}$ \\
\hline$\rho_{0}$ & $\begin{array}{c}0,000 \\
{[-0,0020,002]}\end{array}$ & $\begin{array}{c}0,000 \\
{[0,0000,000]}\end{array}$ & $\begin{array}{c}0,079 \\
{[0,0040,236]}\end{array}$ & $\begin{array}{c}0,078 \\
{[0,0000,219]}\end{array}$ & $\begin{array}{c}0,011 \\
{[0,0020,022]}\end{array}$ \\
\hline$\rho_{1}$ & $\begin{array}{c}1,403 \\
{[1,2561,547]}\end{array}$ & $\begin{array}{c}1,430 \\
{[1,3881,468]}\end{array}$ & $\begin{array}{c}1,580 \\
{[1,4411,738]}\end{array}$ & $\begin{array}{c}1,580 \\
{[1,4301,730]}\end{array}$ & $\begin{array}{c}1,605 \\
{[1,5501,670]}\end{array}$ \\
\hline$\rho_{2}$ & $\begin{array}{c}-0,446 \\
{[-0,579-0,302]}\end{array}$ & $\begin{array}{c}-0,450 \\
{[-0,499-0,410]}\end{array}$ & $\begin{array}{c}-0,605 \\
{[-0,752-0,458]}\end{array}$ & $\begin{array}{c}-0,606 \\
{[-0,750-0,461]}\end{array}$ & $\begin{array}{c}-0,608 \\
{[-0,670-0,554]}\end{array}$ \\
\hline$\sigma_{m}$ & $\begin{array}{c}0,005 \\
{[0,0040,006]}\end{array}$ & $\begin{array}{c}0,005 \\
{[0,0050,005]}\end{array}$ & $\begin{array}{c}0,070 \\
{[0,0610,081]}\end{array}$ & $\begin{array}{c}0,071 \\
{[0,0610,080]}\end{array}$ & $\begin{array}{c}0,072 \\
{[0,0690,074]}\end{array}$ \\
\hline$\delta_{0}$ & $\begin{array}{c}0,000 \\
{[-0,0040,004]}\end{array}$ & $\begin{array}{c}0,000 \\
{[-0,0010,001]}\end{array}$ & $\begin{array}{c}1,935 \\
{[0,8915,160]}\end{array}$ & $\begin{array}{c}2,405 \\
{[0,0875,696]}\end{array}$ & $\begin{array}{c}1,041 \\
{[0,8101,607]}\end{array}$ \\
\hline$\delta_{1}$ & $\begin{array}{c}0,231 \\
{[-0,2570,616]}\end{array}$ & $\begin{array}{c}0,350 \\
{[0,0910,513]}\end{array}$ & $\begin{array}{c}1,632 \\
{[1,6131,638]}\end{array}$ & $\begin{array}{c}1,628 \\
{[1,2371,636]}\end{array}$ & $\begin{array}{c}1,637 \\
{[1,6341,639]}\end{array}$ \\
\hline$\delta_{2}$ & $\begin{array}{c}0,133 \\
{[-0,0730,326]}\end{array}$ & $\begin{array}{c}0,150 \\
{[0,0490,258]}\end{array}$ & $\begin{array}{c}-0,646 \\
{[-0,650-0,644]}\end{array}$ & $\begin{array}{c}-0,646 \\
{[-0,649-0,644]}\end{array}$ & $\begin{array}{c}-0,645 \\
{[-0,646-0,644]}\end{array}$ \\
\hline$\sigma_{n}$ & $\begin{array}{c}0,105 \\
{[0,0200,311]}\end{array}$ & $\begin{array}{c}0,050 \\
{[0,0330,083]}\end{array}$ & $\begin{array}{c}0,095 \\
{[-0,0960,160]}\end{array}$ & $\begin{array}{c}0,117 \\
{[0,087}\end{array}$ & $\begin{array}{c}0,104 \\
{[0,1030,120]}\end{array}$ \\
\hline
\end{tabular}


Phillips para países da Ásia; O mesmo método, com a mesma finalidade, é usado por MACHADO \& PORTUGAL (2014), para a economia brasileira, e por HARVEY (2011), para a economia americana. IRELAND (2007) introduz o componente não observado identificado por BEVERIDGE \& NELSON (1981) em um modelo DSGE para estudar o componente dinâmico da inflação americana.

LAFOURCADE \& DE WIND (2012) constroem um modelo DSGE para a Holanda e o interpretam como um modelo multivariado de componentes não observados. Há justificativa, do ponto de vista da literatura, e também do ponto de vista da qualidade dos resultados obtidos aqui, para o uso dos componentes não observados das séries do PIB real e do PIB nominal no modelo DSGE $^{9}$.

Neste ponto inicia-se a análise estrutural das séries, para isolar os componentes não observados, e a primeira série a ser usada será a do PIB nominal. Primeiro, retira-se a sazonalidade da série usando o código X11, e faz-se a transformação logarítmica. Em seguida, aplicam-se três tipos de dummies: uma dummy permanente, que marca uma quebra estrutural em 2009:2; uma dummy temporária, marcando o período de 2008:1 a 2008:3; e uma dummy para outlier em 1996:4.

Todas as dummies se mostraram fortemente significantes em uma regressão da série do PIB nominal contra elas mesmas. O parâmetro de tendência também é fortemente significante. A dummy de quebra estrutural, mostrando um sinal negativo, reflete a queda da atividade econômica desde então ${ }^{10}$.

A Figura 3 apresenta a decomposição do PIB nominal em seus componentes não observados. O primeiro painel mostra a comparação entre os dados originais e o nível estocástico mais as dummies. O segundo painel mostra a taxa estocástica da tendência, revelando que ela é positiva em todo o período. Isso significa que a tendência é crescente, mas evidencia o seu enfraquecimento a partir de 2010. O componente irregular da série está no terceiro painel.

Os procedimentos para isolar os componentes não observados da série do PIB real, iniciam-se, também, com a retirada do componente sazonal usando o código X11; e faz-se a transformação logarítmica. Em seguida, aplicamse dois tipos de dummies: uma dummy permanente, que marca uma quebra estrutural em 2008:4; duas dummies para outliers, sendo uma em 2009:1 e outra em 2015:2. Todas as dummies são fortemente significantes. O coeficiente da tendência é positivo, porém substancialmente menor do que no caso do PIB nominal.

A Figura 4 contém os componentes não observados do PIB real. No primeiro painel, o PIB trimestral é comparado com o nível estocástico, mais as variáveis de intervenção, mostrando que o componente não observado segue as informações originais, reflexos, ao mesmo tempo, da qualidade do ajustamento e de que o método de decomposição utilizado faz o resultado seguir a dinâmica dos dados. No segundo painel, a taxa de variação da tendência que mostra um crescimento sustentado apenas no período 2003 a 2007 e uma tendência arrefecida de 2010 a 2014 e, daí em diante, um decréscimo mais acentuado. Finalmente, o terceiro painel mostra o componente irregular o

\footnotetext{
${ }^{9}$ Para uma exposição detalhada de como usar o modelo estado espaço em associação com o filtro de Kalmanna extração dos componentes não observados de séries temporais, veja DOAN (2010).

${ }^{10}$ Por motivo de limitação de espaço, não são mostradas as tabelas relativas às estimações dos modelos estado-espaço para isolar os componentes não observados.
} 
Figura 3: Componentes não observados do PIB niminal

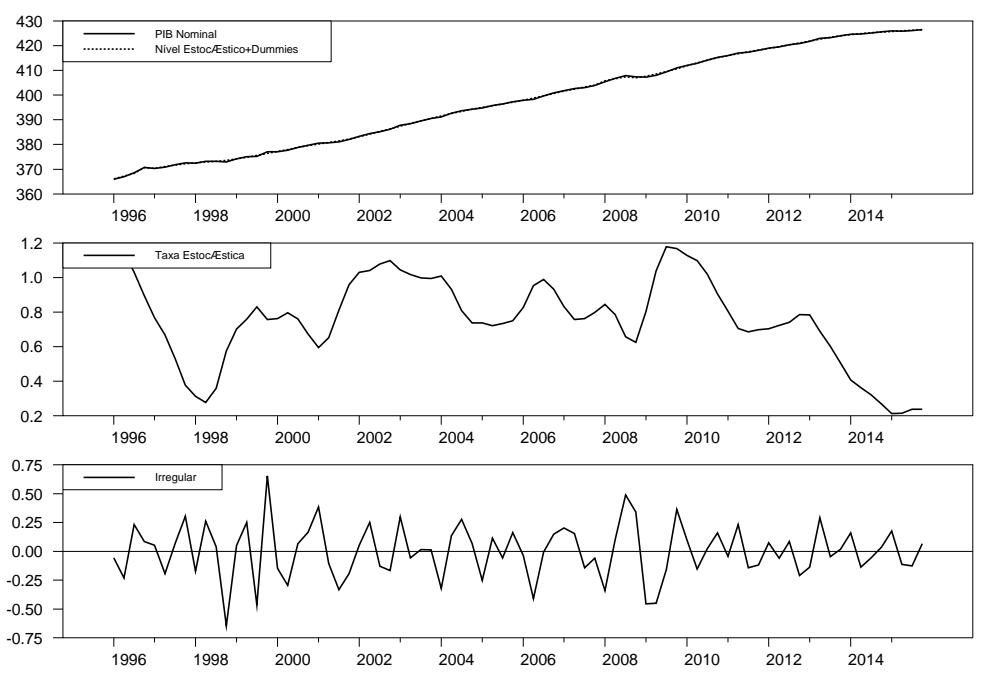

Fonte: Elaborado pelos autores.

qual revela que a instabilidade da economia se tornou mais pronunciada a partir de 2012.

Figura 4: Componentes não observados do PIB real
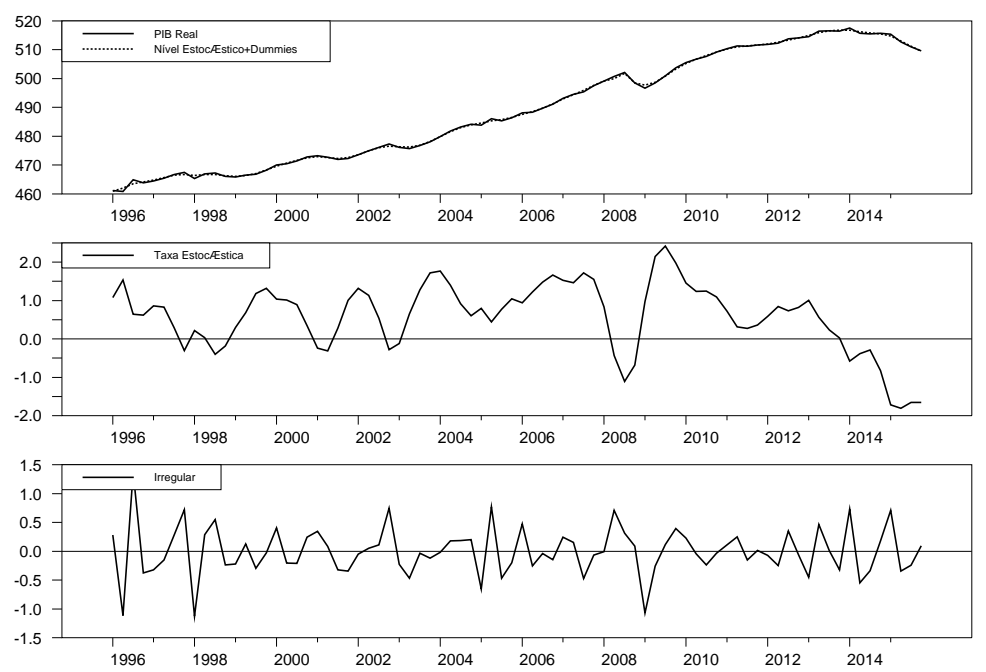

Fonte: Elaborado pelos autores.

\section{Estimação do Modelo DSGE}

Antes de organizar o modelo na forma estado-espaço, especificam-se os valores dos parâmetros que pertencem ao conjunto $\theta$ mencionado anteriormente. Há parâmetros que são determinados exogenamente, como, por exemplo, $K$, que representa o número de setores e, também, a duração máxima de preços, isto é, oito trimestres; assim, também, $\beta=0,99$ a taxa de desconto aplicada, 
no momento em que a firma contrata um novo preço, para atualizar a expectativa de preços e produtos futuros. Os demais parâmetros devem ser buscados em várias outras origens.

Assim, os parâmetros dos processos estocásticos exógenos $A R(2), \rho_{1}, \rho_{2}, \delta_{1}, \delta_{2}$, são estimados a partir dos componentes não observados das séries temporais e, bem assim, as suas variâncias, $\sigma_{m}$ e $\sigma_{n}$. $\zeta$ é estimado junto com o modelo. As distribuições de durações de preços que servem de guesses para as diferentes quantidades de setores são obtidas como proporções aproximadas da distribuição empírica calculada por CARVALHO \& DAM (2010) para os Estados Unidos. Essa iniciativa se fundamenta nas teses sobre as similitudes das estruturas de preços entre o Brasil e aquele país, citadas em estudos (KLENOW \& MALIN 2010, GOUVEA 2007) e constatada através do exercício Monte Carlo realizado neste trabalho.

\section{Resultados}

\subsection{Modelos Heterogêneos}

Apresentam-se as estimativas para $K=4,6$ e 8 . Nesse caso, cada setor tem sua distribuição específica, o que implica diferentes velocidades de ajustamentos de preços. Também será mostrada uma estimativa para uma economia de oito setores onde os preços se ajustam à mesma velocidade, ou seja, o caso em que há homogeneidade na fixação dos preços. Na comparação entre os dois casos, mais adiante neste trabalho, este será denominado de modelo homogêneo, ou de um setor. Os resultados se iniciam com as estimações em que se destaca a heterogeneidade setorial conforme a Tabela 2. Nessa tabela, $E(K)$ é a média das distribuições de durações de preços; $\omega_{i}, i=1, \ldots, 8$, representa a distribuição de durações de preços em cada caso.

O primeiro ponto a notar é que as estimativas convergem em todos os níveis, mostrando as consistências dos modelos. As distribuições de durações de preços extraídas dos dados agregados se conformam fortemente com a distribuição empírica. No caso de oito setores, único para o qual é possível comparação direta dos resultados com CARVALHO \& DAM $(2009,2010)$, para os Estados Unidos, verifica-se uma correlação de 0,85 , sendo que aqui se usou simplesmente máxima verossimilhança, enquanto aqueles autores usaram a metodologia Bayesiana.

Outro ponto importante é a qualidade dos ajustamentos, decorrente, decerto, de se ter aplicado, neste trabalho, os componentes não observados das séries, o que concorda com COMMANDEUR \& KOOPMAN (2007) quando dizem que as propriedades dinâmicas das séries não podem ser observadas diretamente dos dados, e com KICHIAN et al. (2010), segundo quem o componente não observado de uma série representa a sua dinâmica fundamental.

Considerando-se, ainda, a estimação com oito trimestres, como dito antes, a única comparável, observa-se que $28 \%$ dos preços duram um trimestre e $46 \%$ duram dois trimestres, ou seja, $46 \%$ das firmas mudam os preços pelo menos uma vez ao ano. Em CARVALHO \& DAM $(2009,2010)$ são, respectivamente, $28 \%$ e $43 \%$. Essa proximidade dos resultados confirma o que foi encontrado no exercício Monte Carlo, isto é, a semelhança entre as estruturas de preços do Brasil e dos Estados Unidos.

Também assim se pode dizer quanto à duração média dos preços, aproximadamente 12 meses, e o desvio padrão que é de, aproximadamente, oito 
Tabela 2: Distribuição setorial dedurações de preços

\begin{tabular}{|c|c|c|c|c|}
\hline Parâmetros & $\begin{array}{c}\text { Modelo com } \\
4 \text { Setores }\end{array}$ & $\begin{array}{l}\text { Modelo com } \\
6 \text { Setores }\end{array}$ & $\begin{array}{l}\text { Modelo com } \\
8 \text { Setores }\end{array}$ & $\begin{array}{c}\text { Modelo } \\
\text { Homogêneo }\end{array}$ \\
\hline$\zeta$ & $\begin{array}{l}0,206^{* *} \\
(0,009)\end{array}$ & $\begin{array}{l}0,127^{* *} \\
(0,004)\end{array}$ & $\begin{array}{l}0,404^{* *} \\
(0,048)\end{array}$ & $\begin{array}{l}0,360^{* *} \\
(0,017)\end{array}$ \\
\hline$\omega_{1}$ & $\begin{array}{l}0,378^{* *} \\
(0,027)\end{array}$ & $\begin{array}{l}0,477^{* *} \\
(0,006)\end{array}$ & $\begin{array}{l}0,275^{* *} \\
(0,002)\end{array}$ & \\
\hline$\omega_{2}$ & $\begin{array}{l}0,133^{*} \\
(0,056)\end{array}$ & $\begin{array}{l}0,255^{* *} \\
(0,001)\end{array}$ & $\begin{array}{l}0,190^{* *} \\
(0,009)\end{array}$ & \\
\hline$\omega_{3}$ & $\begin{array}{l}0,137^{*} \\
(0,073)\end{array}$ & $\begin{array}{l}0,040^{* *} \\
(0,000)\end{array}$ & $\begin{array}{l}0,020^{* *} \\
(0,000)\end{array}$ & \\
\hline$\omega_{4}$ & $\begin{array}{l}0,352^{* *} \\
(0,004)\end{array}$ & $\begin{array}{l}0,059^{* *} \\
(0,000)\end{array}$ & $\begin{array}{l}0,033^{* *} \\
(0,000)\end{array}$ & \\
\hline$\omega_{5}$ & & $\begin{array}{l}0,077^{* *} \\
(0,004)\end{array}$ & $\begin{array}{l}0,144^{* *} \\
(0,000)\end{array}$ & \\
\hline$\omega_{6}$ & & $\begin{array}{l}0,092^{* *} \\
(0,002)\end{array}$ & $\begin{array}{l}0,123^{* *} \\
(0,000)\end{array}$ & \\
\hline$\omega_{7}$ & & & $\begin{array}{l}0,103^{* *} \\
(0,010)\end{array}$ & \\
\hline$\omega_{8}$ & & & $\begin{array}{l}0,110^{* *} \\
(0,001)\end{array}$ & $\begin{array}{c}1,000 \\
(-)\end{array}$ \\
\hline$\rho_{0}$ & $\begin{array}{l}2,202^{* *} \\
(0,284)\end{array}$ & $\begin{array}{l}2,817^{* *} \\
(0,667)\end{array}$ & $\begin{array}{l}7,229^{* *} \\
(0,107)\end{array}$ & $\begin{array}{l}0,227 \\
(0,306)\end{array}$ \\
\hline$\rho_{1}$ & $\begin{array}{l}1,225^{* *} \\
(0,000)\end{array}$ & $\begin{array}{l}1,222^{* *} \\
(0,001)\end{array}$ & $\begin{array}{l}1,216^{* *} \\
(0,000)\end{array}$ & $\begin{array}{l}1,225^{* *} \\
(0,000)\end{array}$ \\
\hline$\rho_{2}$ & $\begin{array}{c}-0,226^{* *} \\
(0,000)\end{array}$ & $\begin{array}{c}-0,229^{* *} \\
(0,001)\end{array}$ & $\begin{array}{c}-0,234^{* *} \\
(0,000)\end{array}$ & $\begin{array}{c}-0,226^{* *} \\
(0,000)\end{array}$ \\
\hline$\sigma_{m}$ & $\begin{array}{l}0,724^{* *} \\
(0,011)\end{array}$ & $\begin{array}{l}0,702^{* *} \\
(0,026)\end{array}$ & $\begin{array}{l}0,530^{* *} \\
(0,004)\end{array}$ & $\begin{array}{l}0,773^{* *} \\
(0,010)\end{array}$ \\
\hline$\sigma_{n}$ & $\begin{array}{l}1,245^{* *} \\
(0,063)\end{array}$ & $\begin{array}{l}1,951^{* *} \\
(0,132)\end{array}$ & $\begin{array}{l}1,382^{* *} \\
(0,061)\end{array}$ & $\begin{array}{l}3,511^{* *} \\
(0,162)\end{array}$ \\
\hline$\delta_{0}$ & $\begin{array}{l}0,900^{* *} \\
(0,097)\end{array}$ & $\begin{array}{l}0,849^{* *} \\
(0,111)\end{array}$ & $\begin{array}{l}0,853^{* *} \\
(0,081)\end{array}$ & $\begin{array}{l}0,329^{*} \\
(0,165)\end{array}$ \\
\hline$\delta_{1}$ & $\begin{array}{l}1,628^{* *} \\
(0,000)\end{array}$ & $\begin{array}{l}1,629^{* *} \\
(0,000)\end{array}$ & $\begin{array}{l}1,629^{* *} \\
(0,000)\end{array}$ & $\begin{array}{l}1,631 \\
(0,000)\end{array}$ \\
\hline$\delta_{2}$ & $\begin{array}{c}-0,635^{* *} \\
(0,000)\end{array}$ & $\begin{array}{c}-0,634^{* *} \\
(0,000)\end{array}$ & $\begin{array}{c}-0,634^{* *} \\
(0,000)\end{array}$ & $\begin{array}{c}-0,633^{* *} \\
(0,000)\end{array}$ \\
\hline $\begin{array}{l}\text { Iterações para } \\
\text { Convergência }\end{array}$ & 83 & 38 & 37 & 57 \\
\hline $\begin{array}{c}\text { Log Likelihood } \\
\qquad E(K)\end{array}$ & $\begin{array}{c}-145,124 \\
2,463 \\
(1,307)\end{array}$ & $\begin{array}{c}-170,179 \\
2,281 \\
(1,686)\end{array}$ & $\begin{array}{c}-209,592 \\
3,916 \\
(2,566)\end{array}$ & $-180,892$ \\
\hline
\end{tabular}

Fonte: Elaborado pelos autores.

Nota: Parênteses significam desvio-padrão, $\left({ }^{* *}\right)$ significa coeficiente significante a $1 \%$; $\left({ }^{*}\right)$ significa coeficiente significante a $5 \%$. 
meses. O parâmetro $\zeta$, representativo da complementaridade estratégica, se apresentou menor do que 1 em todos os modelos estimados.

\subsection{Comparação Entre os Modelos Heterogêneo e Homogêneo}

Para poupar espaço, só é apresentado aqui o modelo homogêneo que caracteriza uma economia com oito setores na qual a velocidade de ajustamento de preços é a mesma para todos eles. O objetivo neste item é destacar as vantagens do modelo heterogêneo sobre o modelo homogêneo no que concerne às suas implicações para as dinâmicas do produto e da inflação.

Antes, porém, uma rápida visualização da estimativa no caso homogêneo com oito setores (Tabela 2) em que se observam todos os parâmetros fortemente significantes do ponto de vista estatístico, com exceção, apenas, da constante do processo estocástico gerador do choque nominal. Nota-se, ainda, que $\zeta<1$, implicando complementaridade estratégica, isto é, nas decisões sobre ajustamentos de preços as firmas interagem e está presente, portanto, o multiplicador de contratos.

A estratégia usada aqui é comparar entre si os gráficos das FIR, dois a dois, para o mesmo número de setores em cada modelo. Por exemplo, seja uma economia com seis setores; nesse caso, comparam-se as FIR do modelo em que as velocidades de ajustamentos de preços são diferentes (versão heterogênea) com as funções impulso de uma economia, também de seis setores, em que os ajustamentos de preços são uniformes, isto é, uma economia homogênea.

As Figuras 5 a 7, com painéis (a) e (b), contam a história dos efeitos dos choques nominais sobre o produto e a inflação, e os seus graus de persistência, no Brasil, no período de 1996:1 a 2015:4. Do ponto de vista do produto, a comparação entre as versões homogênea e heterogênea parece revelar o esperado em consequência das teorias discutidas ao longo deste trabalho.

Em todos os gráficos que refletem números de setores menores do que oito, o choque nominal faz o produto real crescer por dois, no máximo três trimestres e depois mantém uma trajetória constante que vai além de trinta e dois trimestres. Nota-se que o maior valor de $\zeta$, a complementaridade estratégica, está associado à estimação com oito setores. Esse valor é 0,40 , comparado com 0,21 e 0,13 , respectivamente nas estimativas com quatro e seis setores. $\mathrm{Na}$ Figura 7, após dois meses de crescimento o produto real declina fortemente embora nunca chegue à sua base anterior.

Agora, comparando os gráficos da estimação heterogênea com os da estimação homogênea, não há dúvidas de que os primeiros exibem uma persistência incomparavelmente maior do produto, passando de trinta e dois trimestres, incluindo o de oito setores, o único no qual a trajetória do produto sofre declínio. No caso das estimações homogêneas, o máximo que o produto resiste é doze ou treze trimestres.

Já com respeito às FIR da inflação, não há clareza definitiva sobre qual apresenta mais persistência, isto é, se as do modelo heterogêneo, ou se do modelo homogêneo.

Para se buscar uma melhor aferição desse fenômeno, este trabalho apela para a técnica sugerida por MARQUES (2004), autor que investiga a estreita relação existente entre persistência e reversão à média. Esse procedimento apresenta algumas vantagens interessantes para se estudar o fenômeno. Primeiro, ele permite um melhor entendimento do que a persistência implica em termos da trajetória de qualquer série temporal estacionária; segundo, des- 
Figura 5: Funções impulso-resposta

(a) Heterogêneo 4 setores
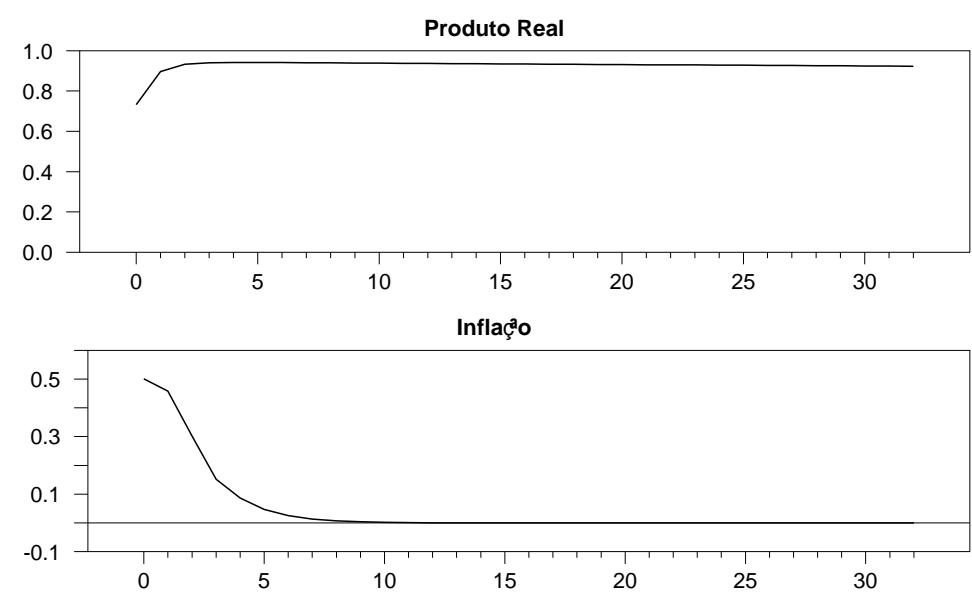

Responses to Nominal

(a) Heterogêneo 4 setores
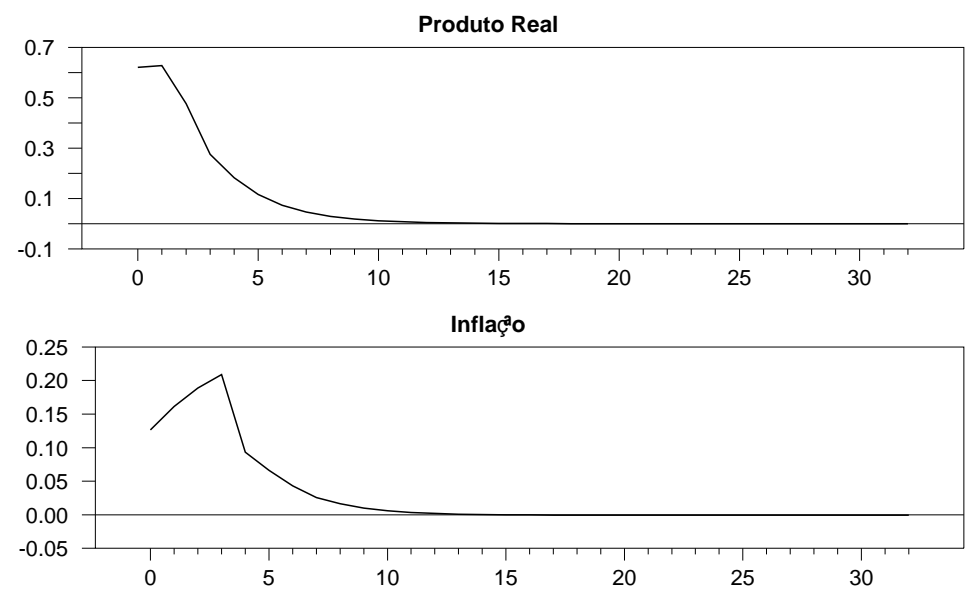

Responses to Nominal

Fonte: Elaborado pelos autores. 
taca o fato de que para medir persistência é necessário primeiro saber como se mede a média de uma série; terceiro, produz uma medida simples para avaliar a persistência da inflação.

Figura 6: Funções impulso-resposta

(a) Heterogêneo 6 setores
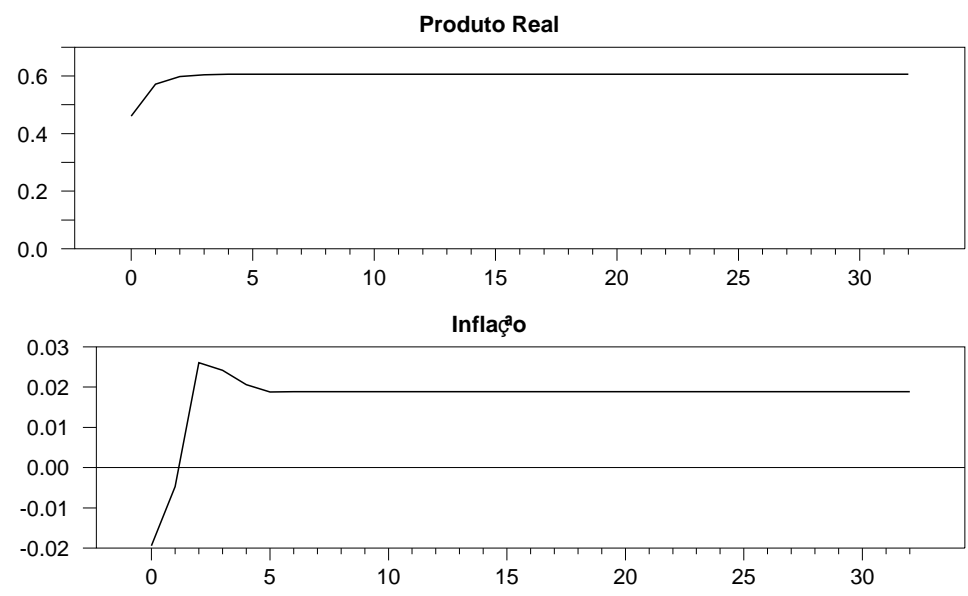

Responses to Nominal

(b) Homogêneo 6 setores
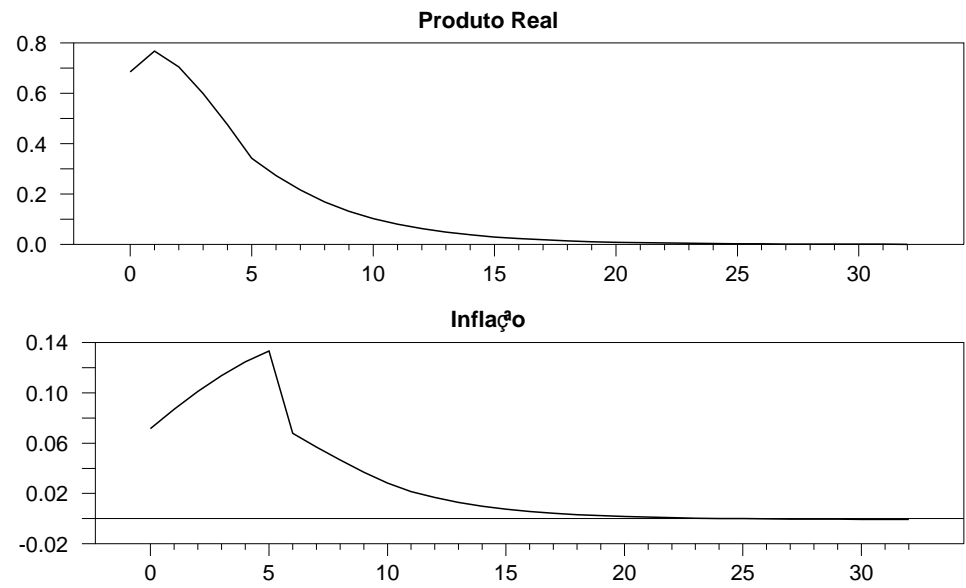

Responses to Nominal

Fonte: Elaborado pelos autores.

A ideia de MARQUES (2004), a esse respeito, é simples. Suponha a seguinte equação:

$$
\Delta y_{t}=\sum_{j=1}^{p-1} \delta_{j} \Delta y_{t-j}+(\rho-1)\left[y_{t-1}-\mu\right]+\epsilon_{t},
$$

na qual $0<\rho<1$. Nessa equação, a presença de reversão à média se expressa em $(\rho-1)\left[y_{t-1}-\mu\right]$. 
Figura 7: Funções impulso-resposta

(a) Heterogêneo 8 setores
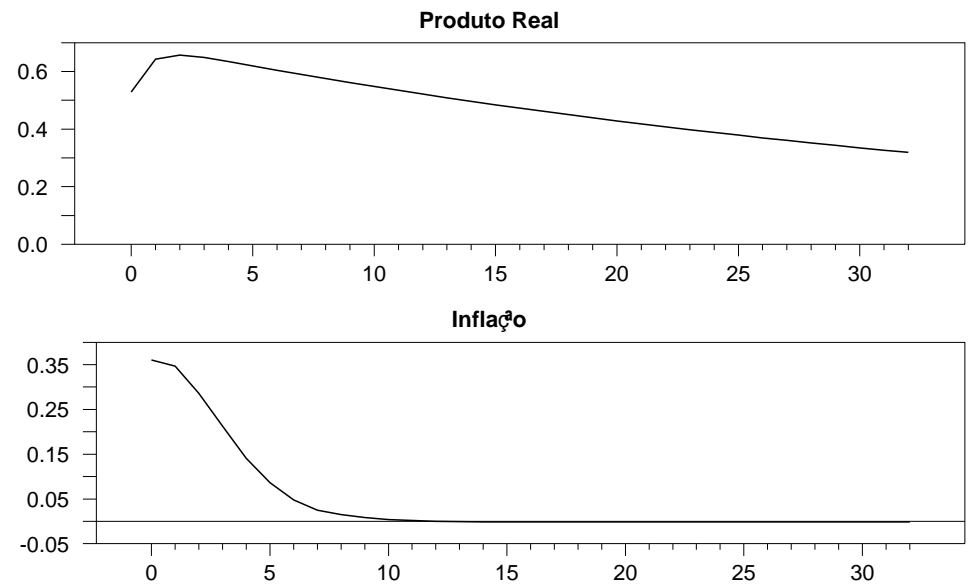

Responses to Nominal

(b) Homogêneo 8 setores
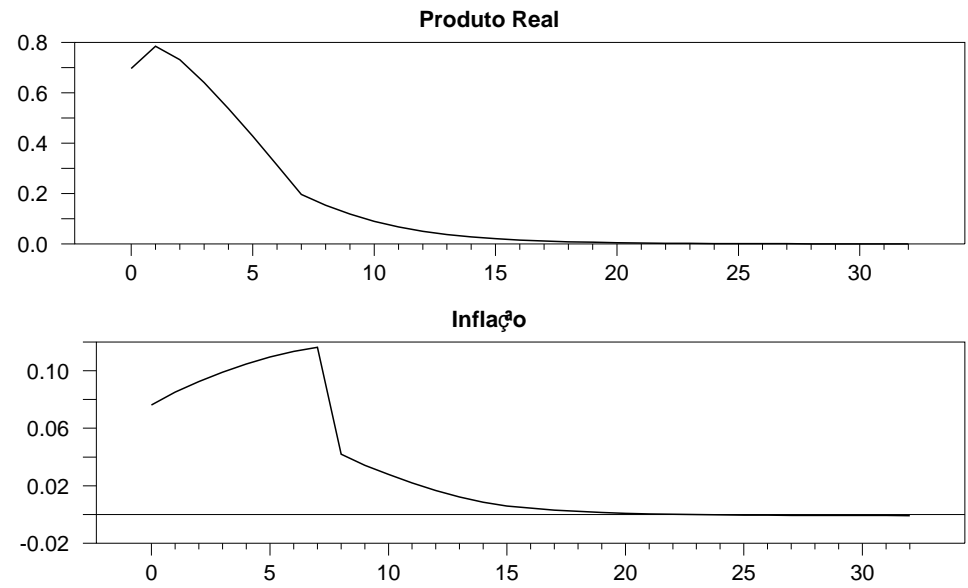

Responses to Nominal

Fonte: Elaborado pelos autores. 
Assim, se no período $t-1$ a série está acima (abaixo) da média, o desvio contribui como uma força que define a variação negativa (positiva) da série no período seguinte, assim conduzindo-a para próximo da média. A dimensão, em termos absolutos de $(\rho-1)$ é decisiva para esse movimento. Assim, persistência geralmente medida como $\rho$ e reversão à média são inversamente correlacionadas, de modo que para duas séries temporais estacionárias quaisquer, a que cruzar menos vezes a média é a mais persistente.

Para examinar a persistência da inflação, segundo essa interessante ideia de MARQUES (2004), usou-se o modelo DSGE para fazer simulações de amostras com 100 observações, de seis séries de inflação envolvendo estimações de quatro, seis e oito setores para os modelos heterogêneo e homogêneo. A Figura 8 é esclarecedora a esse respeito, validando os resultados dominantes na literatura, isto é, a heterogeneidade setorial de rigidez de preços implica maiores persistências tanto do produto real como da inflação.

Figura 8: Avaliação de persistência com amostras simuladas de inflação
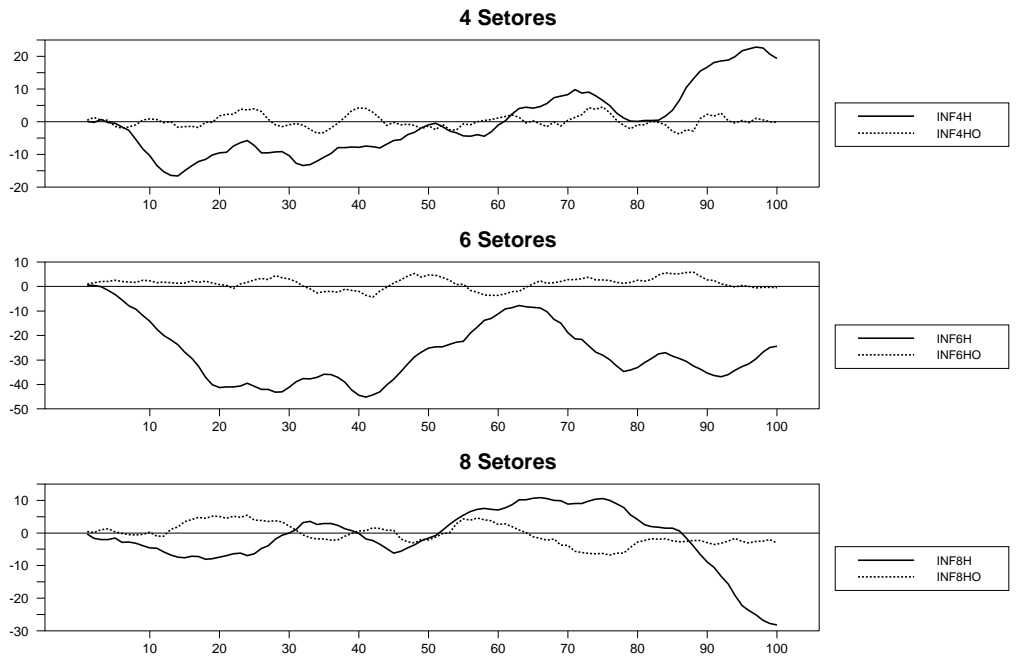

Fonte: Elaborado pelos autores. Nota: inf $k \mathrm{H}$ significa inflação simulada para o modelo heterogêneo de $k$ setores, inf $k \mathrm{HO}$ significa inflação simulada para o modelo homogêneo de $k$ setores.

Na Figura 8, o teste para quatro setores indica que a série inflação do modelo heterogêneo cruza a média apenas 2 vezes, enquanto a série do modelo homogêneo cruza a média 11 vezes. Para seis setores, a série do modelo heterogêneo cruza apenas 1 vez contra pelo menos 4 vezes da série do modelo homogêneo. Para oito setores, são, respectivamente, 4 vezes contra 7 vezes. Parece claro, então, que a heterogeneidade setorial de durações de preços revela mais fortemente a persistência da inflação em comparação com o modelo homogêneo.

\section{Conclusões}

Este trabalho usou componentes não observados de séries temporais representativas dos agregados macroeconômicos produto real e produto nominal para acessar distribuições de durações de preços que lhe são subjacentes. 
Foi usado o modelo DSGE, semi-estrutural, proposto por CARVALHO \& DAM $(2009,2010)$ estimado por máxima verossimilhança. Nas estimações das durações cross-section de preços o ajustamento se revelou de muito boa qualidade com o uso dos componentes não observados das séries de produto real e de produto nominal. Um indicador dessa boa qualidade do ajustamento é o fato de que na estimação heterogênea com oito setores, e, portanto, com duração de preços até 8 períodos, observa-se uma correlação de 0,85 com os resultados de CARVALHO \& DAM $(2009,2010)$, não obstante esses últimos tenham usado a abordagem Bayesiana.

Quanto aos efeitos dos choques nominais, observa-se, como é comum na literatura, que a persistência do produto é incomparavelmente maior nos modelos heterogêneos de seis, sete e oito setores, do que nos modelos homogêneos correspondentes, o que se conclui das próprias FIR. Do ponto de vista da inflação, as FIRs não são conclusivas. Porém, usando-se o modelo de reversão à média (MARQUES 2004, DIAS \& MARQUES 2005) fica bastante clara a superioridade dos modelos heterogêneos.

\section{Referências Bibliográficas}

ALVI, E. (1993), 'Strategic interactions and real rigidity: complementarity between two Keynesian concepts', South Econ J v. 59(n. 3), p. 515-517.

AMITI, M., ITISKHOKI, O. \& KONINGS, J. (2016), 'International shocks and domestic prices: how large are strategic complementarities?', Natl Bur Econ Res p. 54 p.

AOKI, K. (2001), 'Optimal monetary policy responses to relative-price changes', J Monet Econ v. 48(n. 1), p. 55-80.

BALL, L. \& ROMER, D. (1990), 'Real rigidities and the non-neutrality of money', Rev Econ Stud v. 57(n. 2), p. 183-203.

BEVERIDGE, S. \& NELSON, C. R. (1981), 'A new approach to decomposition of economic time series into permanent and transitory components with particular attention to measurement of the business cycle', J Monet Econ v. 7(n. 2), p. 151-174.

BILS, M. \& KLENOW, P. J. (2004), 'Some evidence on the importance of sticky prices', J Polit Econ v. 112(n. 5), p. 947-985.

CALVO, G. A. (1983), 'Staggered prices in a utility-maximizing framework', J Monet Econ v. 12(n. 3), p. 383-398.

CAPORALE, T. \& GRIER, K. B. (2005), 'Inflation, presidents, fed chairs and regime shifts in the US real interest rate', J Money Credit Bank v. 37(n. 6), p. 1153-1163.

CARLSTROM, C. T., FUERST, T. S. \& PAUSTIAN, M. (2009), 'Inflation persistence, monetary policy, and the great moderation', J Money Credit Bank v. 41(n. 4), p. 767-786.

CARVALHO, C. (2006), 'Heterogeneity in price stickiness and the real effects of monetary shocks', J Macroecon v. 6(n. 3), p. 1-58. 
CARVALHO, C. \& DAM, N. A. (2009), 'The cross-sectional distribution of price stickiness implied by aggregate data', Federal Reserve Bank of New York p. 54 p.

CARVALHO, C. \& DAM, N. A. (2010), 'Estimating the cross-sectional distribution of price stickiness from aggregate data', Danmarks Nationalbank p. 42 p.

CARVAlHO, C., DAM, N. A. \& LEE, J. W. (2015), 'Real rigidities and the cross-sectional distribution of price stickiness: evidence from micro and macro data combined', Danmarks Nationalbank p. 55 p.

CHARRY, L., GUPTA, P. \& THAKOOR, V. (2014), 'Introducing a semistructural macroeconomic model for Rwanda', IMF - International Monetary Fund p. 37 p.

COENEN, G. \& LEVIN, A. T. (2004), 'Identifying the influences of nominal and real rigidities in aggregate price-setting behavior', ECB - European Central Bank.

COMMANDEUR, J. J. F. \& KOOPMAN, S. J. (2007), An introduction to state space time series analysis, 1st ed. edn, Oxford University Press, Oxford.

DAVIG, T. \& DOH, T. (2014), 'Monetary policy regime shifts and inflation persistence', Rev Econ Stat v. 96(n. 5), p. 862-875.

DHYNE, E., LE BIHAN, H., ÁlVAREZ, L. J., VERONESE, G., DIAS, D., HOFFMANN, J., JONKER, N., LÜNNEMANN, P., RUMLER, F. \& VILMUNEN, J. (2006), 'Price setting in the Euro area: some stylized facts from individual consumer price data', ECB - European Central Bank p. 50 p.

DIAS, D. \& MARQUES, C. R. (2005), 'Using mean reversion as a measure of persistence', ECB - European Central Bank p. 54 p.

DIXON, H. \& KARA, E. (2005), 'Persistence and nominal inertia in a generalized Taylor economy how longer contracts dominate shorter contracts', ECB - European Central Bank p. p. 47.

DIXON, H. \& KARA, E. (2011), 'Contract length heterogeneity and the persistence of monetary shocks in a dynamic generalized Taylor economy', Eur Econ Rev v. 55(n. 2), p. 280-292.

DOAN, T. A. (2010), RATS handbook for state-space models, 1st ed. edn, Estima, Evanston.

DUPASQUIER, C. \& RICKETTS, N. (1998), 'Non-linearities in the outputinflation relationship: some empirical results for Canada', Bank of Canada p. 23 p.

Estima (2014), RATS users guide, 9th ed. edn, Estima, Evanston.

EVANS, M. D. D. \& LEWIS, K. K. (1995), 'Do expected shifts in inflation affect estimates of the long-run Fisher relation?', J Finance v. 50(n. 1), p. 225253. 
FISCHER, S. (1977), 'Long-term contracts, rational expectations, and the optimal money supply rule', J Polit Econ v. 85(n. 1), p. 191-205.

FLAMINI, A. (2014), 'Heterogeneity in sectoral price stickiness, aggregate dynamics and monetary policy pitfalls with real shocks', Università di Pavia, Department of Economics and Management p. 34 p.

FUJIWARA, I. (2006), 'Evaluating monetary policy when nominal interest rates are almost zero', J Jpn Int Econ v. 20(n. 3), p. 434-453.

GARCIA, R. \& PERRON, P. (1996), 'An analysis of the real interest rate under regime shifts', Rev Econ Stat v. 78(n. 1), p. 111-125.

GOUVEA, S. (2007), 'Price rigidity in Brazil: evidence from CPI micro data', $B C B$ - Banco Central do Brasil p. 47 p.

HARVEY, A. C. (1989), Forecasting, structural time series models and the Kalman filter, Cambridge University Press, Cambridge.

HARVEY, A. C. (2011), 'Modelling the Phillips curve with unobserved components', Appl Financ Econ v. 21(n. 1-2), p. 7-17.

HUIZINGA, J. \& MISHKIN, F. S. (1985), 'Monetary policy regime shifts and the unusual behavior of real interest rates', NBER - National Bureau of Economic Research p. 52 p.

IMBS, J., JONDEAU, E. \& PELGRIN, F. (2011), 'Sectoral Phillips curves and the aggregate Phillips curve', J Monet Econ v. 58(n. 4), p. 328-344.

IRELAND, P. N. (2007), 'Changes in the Federal Reserve's inflation target: causes and consequences', J Money Credit Bank v. 39(n. 8), p. 1851-1882.

JADRESIC, E. (1999), 'Sticky prices: an empirical assessment of alternative models', IMF - International Monetary Fund p. 28 p.

KEYNES, J. M. (1936), Teoria geral de emprego, do juro e da moeda, 1st ed. edn, Fundo de Cultura, São Paulo.

KICHIAN, M., RUMLER, F. \& CORRIGAN, P. (2010), 'Semi-structural models for inflation forecasting', Bank of Canada p. 26 p.

KLENOW, P. J. \& KRYVTSOV, O. (2008), 'State-dependent or timedependent pricing: does It matter for recent U.S. inflation?', Q J Econ v. 123(n. 3), p. 863-904.

KLENOW, P. J. \& MALIN, B. A. (2010), 'Microeconomic evidence on pricesetting', NBER - National Bureau of Economic Research (Working Paper n. 15826), $89 \mathrm{p}$.

KOOPMANS, J. S. \& OOMS, M. (2010), 'Exponentionally weighted methods for forecasting intraday time series with multiple seasonal cycles: comments', Int J Forecast v. 26(n. 4), p. 647-651.

KRZNAR, I. \& MATHESON, T. (2017), 'Financial and business cycles in Brazil', IMF - International Monetary Fund . 
LAFOURCADE, P. \& DE WIND, J. (2012), 'Taking trends seriously in DSGE models: an application to the Dutch economy', DNB - De Nederlandsche Bank p. 86 p.

LUCAS JUNIOR, R. E. (1996), 'Nobel lecture: monetary neutrality', J Polit Econ v. 104(n. 4), p. 661-682.

MACHADO, V. G. \& PORTUGAL, M. S. (2014), 'Phillips curve in Brazil: an unobserved components approach', Estud Econ v. 44(n. 4), p. 787-814.

MARQUES, C. R. (2004), 'Inflation persistence: facts or artefacts?', ECB European Central Bank p. 50 p.

MINELlA, A. \& SOUZA SOBRINHO, N. F. (2009), 'Monetary channels in Brazil through the lens of a semi-structural model', $B C B$ - Banco Central do Brasil p. 57 p.

NAKAMURA, E. \& STEINSSON, J. (2008), 'Five facts about prices: a reevaluation of menu cost models', Q J Econ v. 123(n. 4), p. 1415-1464.

RESCHREITER, A. (2011), 'The effects of the monetary policy regime shift to inflation targeting on the real interest rate in the United Kingdom', Econ Model v. 28(n. 1-2), p. 754-759.

ROMER, D. (2012), Advanced macroeconomics, 4th ed. edn, McGraw-Hill, New York.

SBORDONE, A. M. (2002), 'Prices and unit labor costs: a new test of price stickiness', J Monet Econ v. 49(n. 2), p. 265-292.

SIMS, C. A. (2002), 'Solving linear rational expectations models', Comput Econ v. 20, p. 1-20.

TAYLOR, J. B. (1979), 'Staggered wage setting in a macro model', Am Econ Rev v. 69(n. 2), p. 108-113.

TAYLOR, J. B. (1980), 'Aggregate dynamics and staggered contracts', J Polit Econ v. 88(n. 1), p. 1-23.

TAYLOR, J. B. (1993), 'The use of new macro econometrics for policy formulation', Am Econ Rev v. 83(n. 2), p. 300-305.

TAYLOR, J. B. (1998), 'Staggered price and wage setting in macroeconomics', NBER - National Bureau of Economic Research p. 99 p.

TAYLOR, J. B. (2016), 'The staying power of staggered wage and price setting models in macroeconomics', NBER - National Bureau of Economic Research .

VERMEUlEN, P., DIAS, D., DOSSCHE, M., GAUTIER, E., HERNANDO, I., SABBATINI, R. \& STAHL, H. (2007), 'Price setting in the Euro area: some stylized facts from individual producer price data and producer surveys', ECB - European Central Bank .

WONGWACHARA, W. \& MINPHIMAI, A. (2009), 'Unobserved components models of the Phillips relation in the ASEAN economy', J Econ Manage v. 5(n. 2), p. 241-256. 
WOODFORD, M. (2003), Interest and prices: foundations of a theory of monetary policy, 1st ed. edn, Princeton University Press, Princeton.

WU, S. \& ZENG, Y. (2006), 'The term structure of interest rates under regime shifts and jumps', Econ Lett v. 93(n. 2), p. 215-221.

ÁlVAREZ, L. J., BURRIEL, P. \& HERNANDO, I. (2005), 'Do decreasing hazard functions for price changes make any sense?', ECB - European Central Bank p. 40 p. 
